\title{
DURABILITY OF EXPANDED POLYSTYRENE MORTARS
}

\author{
V. Ferrándiz-Mas, E. García-Alcocel
}

Departamento de Construcciones Arquitectónicas. Universidad de Alicante. Alicante. Spain.

\section{ABSTRACT}

The influence of the addition of various types and various concentrations of expanded polystyrene foam (both commercial and recycled) on the durability of Portland cement mortars is studied. In particular, the microstructure is studied utilizing the following methods: Capillary absorption of water, mercury intrusion porosimetry, impedance spectroscopy and open porosity. In addition, the effects of heat cycles and freeze-thaw cycles on compressive strength are examined. Scanning electron microscopy is used as a complementary technique. An air-entraining agent, water retainer additive and superplasticizer additive are used to improve the workability of mortars. The results show that the presence of expanded polystyrene in mortar results in a decrease in the capillary absorption coefficient. The mercury intrusion porosimetry technique and the equivalent circuits previously used by researchers to interpret impedance spectra of ordinary cementitious materials were found to be inadequate for interpreting the microstructure of mortars with expanded polystyrene. This is due to the polymeric nature as well as the internal porous structure of expanded polystyrene. A slight increase of compressive strength is observed in mortars with expanded polystyrene subjected to heat cycles. The compressive strength of mortars subjected to freeze-thaw cycles likely improves because expanded polystyrene particles absorb part of the pressure of ice crystallization. It is concluded that the durability of mortars improve with the presence of expanded polystyrene, making them viable for more sustainable usage in masonry, stucco and plaster mortars.

\section{Keywords:}

Mortar, Portland cement, expanded polystyrene (EPS), waste, durability, microstructure, porosity, compression testing. 


\section{Introduction}

Expanded polystyrene foam (EPS) is a thermoplastic polymer with a closed cellular structure. It is biologically inert and non-toxic. EPS has interesting properties such as being of low density, thermal insulation, hydrophobicity and chemical resistance when exposed to acids and alkalis. EPS may be granulated into small particles that can be considered as non-absorbent and a lightweight polymeric aggregate (less than $300 \mathrm{Kg} / \mathrm{m}^{3}$ density) [1-2]. These aggregates may be used to produce light building materials.

Research in the field of concrete incorporating EPS as an aggregate is mainly devoted to the characterization of the mechanical properties of the concrete and trying to improve these properties by characterizing them for various EPS grain sizes, additives, and other additions such as fly ash and silica fume [3-5]. Other studies characterize both mechanical and thermal EPS concrete properties using simultaneous optimization of these properties with respect to EPS parameters. These studies proposed modelling methods to predict and optimize these properties [6]. Recent articles show the adequacy of wet concrete of a self-compacting lightweight structural made with nano- $\mathrm{SiO}_{2}$ and EPS [7].

Other studies have used EPS beads to design thermal insulator composites made with foamed cement pastes as a matrix, using granules of EPS as filler, along with additives to prevent segregation and improve adherence [8]. EPS has also been used for the manufacture of gypsum and plaster plates and panels [9] with the plaster matrix reinforced with polypropylene fibres in the manufacture of industrial components [10] and with mixtures of fly ash and metakaolinite to obtain light inorganic polymeric materials (light geopolymers) [11].

Expanded polystyrene foam (EPS) represents $0.1 \%$ of total municipal solid waste. The recycling of solid polymeric wastes as components of mortars and concretes requires research that differentiates the characteristics of the polymers that improve their incorporation into cementitious materials and demonstrates the value added through their use. Previous work has identified the influence of the addition of various types and dosages of EPS, both commercial and recycled, on physical and mechanical characteristics of Portland cement mortars. These studies have concluded that it is possible to produce mortars with mechanical properties adequate for use in masonry, rendering and plaster mortars [12] using a high content of EPS waste. 
The main aim of this study is to evaluate the influence of the addition of EPS on the durability of Portland cement mortars in order to demonstrate their viability and enhanced usage in the fabrication of mortars suitable for use as masonry, stucco and plaster mortars. To do this, the microstructure of mortars containing various types and EPS dosages were studied using water capillary absorption, mercury intrusion porosimetry and impedance spectroscopy. Additionally, the compressive strength was tested after subjecting the mortar to heat cycles and freeze-thaw cycles.

\section{Experimental programme}

\subsection{Material and sample preparation}

The following materials were used for this study: Portland cement type CEM I 52.5R, silica sand in compliance with the European standard given in EN 196-1:2005 [13], distilled water, several types of EPS, and three types of additives.

The types of EPS used were: commercial expanded polystyrene (EPSc), pre-expanded polystyrene (EPSpex) and ground expanded polystyrene from clean recycled waste (EPSw). In all cases the EPS used is white, with a $100 \%$ material loss on ignition and a softening point temperature between 80 and $10^{\circ} \mathrm{C}$. Other properties of EPS particles are given in table 1.

The three types of additives used were: an air-entraining agent (A), Basf Rheomix 934; a water retainer additive $(\mathrm{R})$, Hydroxypropyl methyl cellulose; and a superplasticizer additive (F), Basf Rheomix GT 205 MA.

Table 2 shows the EPS dosage as addition percentage of total mortar volume, considering as such the apparent volume of sand $(\mathrm{v} / \mathrm{v} \%)$ and the additive dosage as a percentage of the weight of the cement. The mortars were prepared with a cement/sand/water ratio (by weight) of 1:3:0,5. All mortars studied were prepared with the following amounts of materials: $450 \mathrm{~g}$ of CEM I 52,5R, $1350 \mathrm{~g}$ of silica sand of $1,67 \mathrm{~g} / \mathrm{cm}^{3}$ density and $225 \mathrm{~g}$ of distilled water.

Mortar workability was tested to determine the amounts of EPS and additive necessary to obtain adequate consistency of fresh mortar through the use of a flow table according to EN 1015-3:2007 [14]. These results have been published in a previous study [12]. Using the results of this study, the additive dosages given in table 2 were chosen and are shown as a percentage of the weight of the cement $(w / w \%)$. All mortars were manufactured according to the European standard EN 196- 
1:2005 [13]. After preparation, the specimens were cured under water at a temperature of $20 \pm 2$ ${ }^{\circ} \mathrm{C}$ for various curing times depending on the test in which the sample was used.

\subsection{Test methods}

\subsubsection{Capillary absorption}

Capillary water absorption of mortars has been determined according to EN 1015-18:2003 [15]. In order to do this, three specimens of $4 \times 4 \times 16 \mathrm{~cm}$ were made for each of the dosages shown in Table 2. The specimens were kept in moulds for 2 days, after which they were removed from their moulds and were cured underwater for 5 days. After the curing period, specimens were cut in half, and dried in an oven at a temperature of $65 \pm 2^{\circ} \mathrm{C}$. After drying, the lateral sides of each specimen were sealed with an adhesive plastic film to restrict the water flow along the longitudinal axis. The water flux through the specimen was measured by partial immersion of the samples at a depth of 5 $\mathrm{mm}$. The gain in water mass was measured by weighing the samples 10 and 90 minutes after submersion. The capillary absorption coefficient, $\mathrm{C}_{90}$, was estimated from the slope following to the equation $\mathrm{W}=\mathrm{a}+\mathrm{Ct}^{1 / 2}$, where $\mathrm{W}\left(\mathrm{Kg} / \mathrm{m}^{2}\right)$ is the capillary absorption, a $\left(\mathrm{Kg} / \mathrm{m}^{2}\right)$ is the initial absorption, $\mathrm{C}\left(\mathrm{Kg} / \mathrm{m}^{2} \mathrm{~min}^{0,5}\right)$ is the capillary absorption coefficient and $\mathrm{t}(\mathrm{min})$ is the absorption time, using the equation: $C_{90}=0,1\left(M_{2}-M_{1}\right)$, where $M_{1}$ is the weight of the specimen after 10 minutes of testing, and $\mathrm{M}_{2}$ is the weight of specimen after 90 minutes of testing according to EN 1015-18:2003 [15].

\subsubsection{Impedance spectroscopy (IS)}

The microstructure of the mortars was studied using impedance spectroscopy for mortars containing $70 \%$ of each of the three types of EPS and additives, as shown in Table 2 . For this study a cylindrical specimen of $10 \mathrm{~cm}$ diameter and $16 \mathrm{~cm}$ in height was manufactured for each of the dosages. After 24 hours, the specimens were removed from their moulds and cut into $1 \mathrm{~cm}$ thick disks. Each of the disks was then cured underwater for 120 days. After curing, the discs were removed from the water bath, and the surface of each disk was then dried with paper. The impedance spectra were obtained for each disc using an Agilent 4294A impedance analyzer. This 
model permits capacitance measurements in the range from $10^{-14}$ to $0.1 \mathrm{~F}$ and has a maximum resolution of $10^{-15} \mathrm{~F}$.

The impedance was measured through both direct contacting and through the non-contacting method, as shown in Figure 1. The direct contact measurements in Figure 1a were taken by application of an electrical perturbation through $7 \mathrm{~cm}$ diameter flexible graphite electrodes. These electrodes were placed in direct contact with each side of the sample disc. For the non-contacting measurements, shown in Figure 1b, the sample-electrode interface is isolated by a $100 \mu \mathrm{m}$ thick layer of acetate. The impedance of the sample is obtained by subtracting the previously-obtained impedance of the acetate layer from the total measured impedance.

To interpret and study the impedance spectra, two previously proposed equivalent circuits were used [16] as shown in Figure 2. These circuits have been utilized extensively for Portland cement pastes, mortars and concrete [16-21]. In this work the parameter $R_{1}$ was analyzed using the contacting method (shown in Figure $2 a$ ). The parameters $C_{1}, C_{2}$ and $R_{2}$ were obtained using noncontacting measurements, as shown in Figure $2 \mathrm{~b}$, given that it can be obtained a biggest measurement sensitivity calculating these parameters using the method that avoid the contact between sample and electrode.

In terms of the physical significance of these equivalent circuits, the resistance $R_{1}$ depends on the electrolyte in the pores and is associated with the volume of interconnected pores [16] that traverse the length of the specimen. The resistance $R_{2}$ is associated with the electrolyte in the occluded pores, or the pores that do not contribute to the electrical conductivity across the sample [18]. The capacitance $C_{1}$ is associated to the dielectric response of the solid fraction of the sample, and could be used as a parameter to estimate the solid and pore fractions of the material [16]. Its value decreases as the thickness and porosity of the sample increases. The capacitance $C_{2}$ has been shown to be associated to the surface of pore walls in contact with the electrolyte filling the pores $[19,21]$. Its value increases with electrolytic occupancy of the pores and with increasing thickness of the sample. The analysis of the equivalent parameters using experimental measurements was made with the software program Zfit, developed by the Department of Construction Engineering, Public Works and Urban Organization at the University of Alicante. 


\subsubsection{Mercury intrusion porosimetry (MIP)}

In order to complete the microstructural characterization of the mortars, the Mercury Intrusion Porosimetry technique was employed. This technique was employed in mortars made with $70 \%$ of EPS (see table 2). The porosimeter employed was a Micromeritics Autopore IV 9500 which permits pore analysis in the pressure range of $14000 \mathrm{~Pa}$ to $225 \mathrm{MPa}$ and pore diameter determination over the pore diameter range of $0,9 \mathrm{~mm}$ to $5 \mathrm{~nm}$. The porosity and the pore size distribution of each sample were tested twice using two different pieces of the same sample. The pore size distributions of the mortars were calculated from the applied pressure via the Washburn equation [22] assuming a contact angle of $130^{\circ}$. The pore size distribution of samples was computed using the following diameter intervals: $<10 \mathrm{~nm}, 10-100 \mathrm{~nm}, 100 \mathrm{~nm}-1 \mu \mathrm{m}, 1-10 \mu \mathrm{m}, 10 \mu \mathrm{m}-0.1 \mathrm{~mm}$ y $>0.1 \mathrm{~mm}$. The samples were oven dried at a temperature of $65 \pm 2 \stackrel{\circ}{\circ}$ before be tested.

\subsubsection{Open porosity}

The open porosity of the specimens was determined from portions of the samples manufactured for the microstructure studies. For this measurement, a dry sample was weighed $\left(m_{\text {dry }}\right)$ and immersed in water until it reached total saturation. The saturated sample was again weighed $\left(\mathrm{m}_{\mathrm{sat}}\right)$, and finally the weight of the sample immersed in water $\left(\mathrm{m}_{\mathrm{i}}\right)$ was obtained using a hydrostatic scale (saturated and submerged). The open porosity was then calculated according to the expression: open porosity $(\%)=\left(\left(m_{\text {sat }}-m_{\text {dry }}\right) /\left(m_{\text {sat }}-m_{i}\right)\right) \times 100$.

\subsubsection{Heat and Freeze-thaw cycles}

The dependence of the mechanical behaviour of the mortars as a function of temperature was determined by subjecting the mortar specimens to heat and freeze-thaw cycles. The tests were conducted according to the procedure in EN 196-1:2005 [13] to evaluate the change in compressive strength. Nine $4 \times 4 \times 16 \mathrm{~cm}$ specimens were made for each of the EPS dosages shown in table 2. Specimens were cured underwater at $20 \pm 2^{\circ} \mathrm{C}$ for 28 days. After curing, three specimens (for each dosage) were subjected to heat cycles according to the following process: the samples were put into the oven at $60 \pm 5{ }^{\circ} \mathrm{C}$ for 18 hours, then removed from the oven and kept at 
room temperature $\left(20 \pm 2^{\circ} \mathrm{C}\right)$ for 6 hours. After 25 of these heat cycles, the specimens were tested under compression. Another three specimens (for each dosage) were subjected to freeze-thaw cycles. In this case an adaptation to the UNE 67028 EX: 1997 standard for clay bricks was made [23]. After curing, the samples were completely immersed in water at $15 \pm 5^{\circ} \mathrm{C}$ for 48 hours. Next, freeze-thaw cycles were carried out according to the following process: The samples were removed from the water and drained. Then samples were put into the freezer at $-15 \pm 5^{\circ} \mathrm{C}$ for 18 hours. Finally, they were removed from the freezer and completely immersed in water at $15 \pm 5^{\circ} \mathrm{C}$ for 6 hours. After 25 cycles, they were tested under compression. The remaining three specimens, which hadn't been subjected to cycles, were tested for compressive strength after 28 days of curing at room temperature $\left(20 \pm 2^{\circ} \mathrm{C}\right)$ according to EN 196-1:2005 [13].

\section{Results and discussion}

\subsection{Capillary absorption}

Figure 3 shows the capillary absorption coefficient $\left(\mathrm{C}_{90}\right)$, for mortars made with various types and dosages of EPS without additives, as well as the error bands computed with a $95 \%$ probability confidence interval. From this figure, it may be seen that the coefficient $\mathrm{C}_{90}$ decreases for mortars made with $70 \% E P S c$ and $70 \% E P S w$ with respect to the values of $\mathrm{C}_{90}$ for the control mortar $(0 \%$ EPS and $0 \%$ additive). Significant differences with the control mortar were not detected for the rest of mortars. Previous studies of porosity in these mortars show this same trend [12]. Therefore, high dosages of EPS in mortar improve their durability.

Figure 4 shows the influence of various types of additives on the capillary absorption coefficient on the $0 \%$ EPS mortar and on mortars made with $70 \%$ of the varying types of EPS. In mortars without EPS, the capillary absorption coefficient is significantly reduced because of additives. This fact could be due to improvements in both the workability [12] as well as the microstructure of the cement paste. The improvement in the microstructure is confirmed by analysis of the pore size distribution using mercury intrusion porosimetry in mortars with additives but without EPS, as shown in Figure 5. Generally, the addition of additives decreases the volume of pores that are of 
less than $100 \mathrm{~nm}$ in size, while increasing the volume of pores larger than $100 \mathrm{~nm}$. As a result, the capillary absorption coefficient decreases by adding additives.

Returning to figure 4, it can seen that additives in mortars made with $70 \%$ EPS significantly decrease the value of $\mathrm{C90}$. As a result, durability improves and is comparable to the durability of the $0 \%$ EPS mortar with additives. Both the particles of EPS and the air bubbles generated by the air-entraining agent interrupt the continuity the capillary network. For this reason, the lowest capillary absorption coefficients are observed with this additive. When EPSpex is added to the mortar, a greater number of EPS particles are required to obtain the same volume of EPS, because EPSpex has the highest density and intermediate size particle (see table 1). This may explain the low values obtained for the capillary absorption coefficient for mortars made with EPSpex. Intermediate values of $\mathrm{C}_{90}$ are observed for mortars made with EPSw. The largest values of $\mathrm{C}_{90}$ are observed for mortars made with EPSc which have a lower density and fewer EPS particles for the same volume because of the biggest size.

\subsection{Mercury intrusion porosimetry (MIP)}

Table 3 gives the results for open porosity (section 2.2.4) and total porosity obtained by mercury intrusion porosimetry after a 120 day curing period. The values for porosity obtained by mercury intrusion porosimetry were higher than those obtained through the open porosity method. This is due to the fact that mercury under pressure accesses a greater pore volume than water, which only penetrates the pore network by diffusion. As a result, the use of mercury results in greater connectivity in the pore network. This is clearly seen in the control mortar where the difference between porosities obtained using the two methods is about $14 \%$.

In the case of mortars made with EPS, the differences in porosity obtained through the two methods are higher than those observed for the control mortar. The presence of additives does not change this trend. These differences are not only attributable to the microstructure of the mortar paste. This fact is supported by the SEM images of these mortars shown in Figure 7. In these images it is apparent that the EPS particles have a porous structure into which the mercury can penetrate. The internal cellular structure of the EPS may be observed in Figure 7a. In addition, it should also be noted that the increased mercury intrusion pressure can break the EPS particles 
allowing a penetration of a higher volume of mercury into the sample. In Figure $7 \mathrm{~b}$ it can be observed that the fine polymer wall that separates the cells may easily be broken by the increase of pressure imposed by mercury intrusion. This behaviour results in an increase of the porosity obtained with this technique over the open porosity technique. For this reason, the technique of mercury intrusion porosimetry is not considered appropriate to study the microstructure of EPS mortars.

\subsection{Impedance spectroscopy.}

Table 4 shows impedance parameters and open porosity after a 120 day curing period. In order to make the analysis easier, values for the capillary absorption coefficient $\left(\mathrm{C}_{90}\right)$, discussed previously, are included in this table.

Regarding the parameters obtained in the impedance spectroscopy study, the volume of interconnected pores may be estimated from $R_{1}$ parameter. This parameter is related to the electrolyte which fills the pores and is specifically associated with interconnected pores [16]. R1 is also related to changes in the dimensions of the pores [18]. Because the samples are submerged in water for a 120 day curing period, the pores are completely saturated and, as such, variations in the resistance, R1, are associated only with changes in the volume of the interconnected pores. The resistance, $R_{1}$, would be expected to increase with decreasing open porosity or decreasing interconnected pore size in the sample, because in these cases, the amount of electrolyte in the interconnected pores is reduced. In general, mortars with EPS follow this trend, regardless of the type of EPS, except for mortars made with superplasticizer additive. The behaviour of these mortars may be explained by changes in the dimensions of the pores caused by the additive [2425]. This hypothesis wasn't proven in this work because Mercury Intrusion Porosimetry is not a suitable technique for determining the pore size distribution in mortars with EPS, as was discussed in the previous section. $R_{1}$ may also be related to the capillary absorption coefficient $C_{90}$. Generally, an increase in $\mathrm{R}_{1}$ corresponds to a decrease in $\mathrm{C}_{90}$. However, this behaviour was not fulfilled by EPS mortars. This fact could be explained as follows: The impedance parameters obtained testing only an EPS sample and testing a control mortar differ greatly, as may be seen in 
table 4. Effectively, the EPS mortars do not constitute a homogeneous solid phase, which would be expected in mortars formed by materials with similar properties. According to the capillary absorption results, the EPS and the mortar cannot be treated alike. The EPSc and EPSpex particles retain their original closed and hydrophobic spherical shape in the mortar specimens employed in testing. These spherical particles obstruct the capillary network, reducing the capillary absorption coefficient $\mathrm{C}_{90}$. In the grinding process used to obtain EPSw, the EPS particles, initially closed and spherical, are broken up and form an open cellular structure. In mortars made with EPSw these particles also obstruct the capillary pore network but in spite of their open cellular structure do not absorb water by capillary action as the surface tension of water is much greater than the surface energy of EPSw particles. For these reasons, $R_{1}$ and $C 90$ are not related in mortars made with EPS. The $R_{2}$ parameter can be related to the occluded porosity in mortar, that is, with pores that do not contribute to the electrical connection of the sample [18]. In general, the $\mathrm{R}_{2}$ parameter and the occluded porosity are inversely related. For a given type of EPS, the mortars with the highest occluded porosity should be those made with the air-entraining agent. However, this trend is only fulfilled by mortars made with EPSw.

The parameter $C_{1}$ could be used to estimate the solid and porous fraction of the material [16]. In this case, $\mathrm{C}_{1}$ and the sample porosity would be expected to be inversely related. This trend is only fulfilled by mortars with EPSc. $\mathrm{C}_{2}$ is related to wet pore surface area. For samples with similar $\mathrm{R}_{1}$, the largest $\mathrm{C}_{2}$ values should be associated with samples with very rough pores with a large pore surface area, which should lead to an increase in the capillary absorption coefficient. This trend is observed in mortars made with EPSw and additives.

The results of this section show that there aren't clear relationships among the impedance parameters and the microstructural characteristics in this study. The differences in the dielectric properties between EPS and cementitious materials cause significant variability in the dielectric properties of the EPS mortar system, which doesn't permit modelling of these mortars as a homogeneous phase. The lack of symmetry of the system, that is, homogeneity in the dielectric properties, according to the effective medium theory [26], justifies the necessity of proposing alternate equivalent circuits for the interpretation of the impedance spectra that discriminate 
between cementitious and polymer materials. The development of these circuits falls outside of the scope of this study and should be addressed in future study.

The results presented here concerning the microstructure of EPS mortars show that clear relationships do not exist between the studied parameters. In addition is not possible justified the observed trends by Mercury Intrusion Porosimetry. For all of these reasons, the study of impedance spectra by the equivalent circuits, thoroughly used in the literature for Portland cement pastes, mortars and concrete, were found to be inadequate for interpreting the microstructure of EPS mortars.

\subsection{Heat and freeze-thaw cycles.}

Figure 6 shows the compressive strength of mortars made with various dosages of EPSw before cycles $(\mathrm{Sc})$, after heat cycles $\left((\mathrm{Sc})_{\text {heat }}\right)$ and after freeze-thaw cycles $\left((\mathrm{Sc})_{\text {cold }}\right)$. The behaviour of mortars made with commercial EPS (EPSc and EPSpex) is very similar. The temperature used for heat cycles is $60 \pm 5{ }^{\circ} \mathrm{C}$ and was chosen due to the polymeric nature of the EPS. Figure 6 shows that EPS has a negative effect on the compressive strength of mortars. This fact is showed by Sc decreasing as the dosage of EPS increases. However, EPS has a positive influence on the compressive strength in mortars after heat cycles. Since the chosen temperature of $60{ }^{\circ} \mathrm{C}$ increased the compressive strength of the control mortar slightly, is able analyzed the combined influence of EPS and heat cycles in compressive strength. The increase observed in compressive strength of mortars containing EPS, and therefore in their durability, can therefore be explained by two possible causes. On one hand, the microstructure of the hydrated cement paste may improve because the higher temperature allows a more extended hydration reaction. On the other hand, the hydrated cement paste-EPS interface may improve, allowing more adherence between these phases. The second assertion can be confirmed by the SEM image in Figure 7, which shows a sample made with $70 \%$ EPSw after heat cycles. In this image, an adequate adherence between EPS and cement paste (Figure 7c) is evident.

The behaviour of EPS mortars after freeze-thaw cycles is also shown in Figure 6. By comparing the values of $(\mathrm{Sc})_{\text {cold }}$ (for mortars containing EPS) and Sc for a control mortar( $\left.0 \% \mathrm{EPS}\right)$, it can be seen that after freeze-thaw cycles in mortars made with EPS, the higher the dosage of EPS, a 
higher loss in compressive strength is obtained being above $50 \%$ at the highest EPS dosages. This behaviour may be attributed to the poor workability of these mortars, making them more heterogeneous and dispersed, facilitating the formation of micro cracks by the expansive effect of ice. The effect of freeze-thaw cycles on these mortars can be seen by comparing the values $(\mathrm{Sc})_{\text {cold }}$ and Sc, for a given mortar. The effect of the freeze-thaw cycles on the control mortar produces a loss of around $25 \%$ in compressive strength. However, the loss of compressive strength in 10 and $30 \%$ EPSw mortars it is only $7 \%$ and $11 \%$ respectively. Mortars with $50 \%$ EPSw even show a small gain (5\%). In these cases, EPS in mortars maintains or improves their durability to freeze-thaw cycles. The presence of EPS in mortars has a positive influence because EPS absorbs part of the ice crystallization pressure. As a result, the effect of freeze-thaw cycles in mortars with EPS is lower than in control mortar and the deterioration decreases. This again highlights the positive effect of EPS on the durability of mortars. The exception is for mortars containing $70 \%$ EPSw, where the compressive strength loss is greater than in the control mortar, at $31 \%$. This is again due to the low workability and high heterogeneity of these mortars that reinforces the need to use additives, especially in mortars with high dosage of EPS.

Figure 8 shows compressive strength values for mortars made with 0\% and $70 \%$ EPSw and various additives before cycles $(\mathrm{Sc})$, after heat cycles $\left((\mathrm{Sc})_{\text {heat }}\right)$ and after freeze-thaw cycles $\left((\mathrm{Sc})_{\text {cold }}\right)$. The Sc values for 0\%EPS mortars shows the influence of a given additive on the control mortar (0\%EPS and $0 \%$ additives). The compressive strength improve using superplasticizer additive $(F)$ compared with the control mortar. Nevertheless, with the presence of air-entraining agent $(A)$ and the water retainer additive $(R)$, the compressive strength decrease, which losses of around $52 \%$ and $8 \%$ respectively. The air-entraining agent $(A)$ introduces air bubbles that assist in this reduction of compressive strength, so this result is expected. The $(\mathrm{Sc})_{\text {heat }}$ values for $0 \% \mathrm{EPS}$ mortars made with air-entraining agent $(A)$ and superplasticizer additive $(F)$ show that after heat cycles almost retain their compressive strength. Only 0\% EPS mortars with water retainer additive (R) show losses of around $15 \%$. If the value $(\mathrm{Sc})_{\text {heat }}$ for $0 \%$ EPS mortars and Sc for control mortar are compared, it may be seen that the combined influence of additives and heat cycles in $0 \%$ EPS mortars produce in compressive strength losses around $52 \%$ and $22 \%$ for mortars with $(A)$ and $(R)$ 
additives respectively. Only mortars made with superplasticizer additive (F) improve their behaviour relative to the control mortar.

The Sc values for $70 \% E P S w$ mortars show that the use of additives improve the compressive strength for mortars made with water retainer additive $(R)$ and superplasticizer additive $(F)$. Mortars made with air-entraining agent $(\mathrm{A})$ have losses in their compressive strength around 53\% compared to the $70 \%$ EPSw mortars without additive. This result is due to the influence of the aforementioned air-entraining agent. By comparing Sc values for $70 \% \mathrm{EPSw}$ and Sc for control mortar, it seems that the use of additives in mortars with EPS do not compensate the losses in compressive strength produced by the presence of EPS. The greatest losses are observed in $70 \%$ EPSw mortars with an air entraining agent additive (A). By comparing Sc values for $70 \%$ EPSw with additives and Sc for 0\%EPS with the same additives, it may be seen that the greatest losses are obtained in $70 \%$ EPSw mortars with a superplasticizer additive $(F)$. The influence of the EPS is so much the worse for mortars made with superplasticizer additive $(F)$. The $(S c)_{\text {heat }}$ values for $70 \%$ EPSw mortars show that heat cycles did not cause significant differences in the compressive strength of mortars made with EPS and additives. Mortars made with EPS and a superplasticizer additive (F) show increases of $5 \%$ in their compressive strength. Losses of 7 and $24 \%$ were obtained in mortars made with water retainer additive $(R)$ and air-entraining agent $(A)$, respectively. However, the $(\mathrm{Sc})_{\text {heat }}$ values for $70 \% E P S w$ mortars made with water retainer additive (R) and superplasticizer additive (F) are better than Sc value for $70 \%$ EPSw without additives, showing the beneficial effect of these additives in EPS mortars subjected to heat cycles.

The $(\mathrm{Sc})_{\text {cold }}$ values show the behaviour for mortar subjected to freeze-thaw cycles. Comparing $(\mathrm{Sc})_{\text {cold }}$ values and Sc values for the same mortar, it may be seen that freeze-thaw cycles reduce the compressive strength of $0 \%$ EPS mortar made with additives by $32 \%$ for mortar with water retainer additive $(R)$, and $22 \%$ for mortars with air entraining agent $(A)$ and superplasticizer additive (F). In mortars with $70 \% E P S w$ it may be seen that freeze-thaw cycles cause losses in compressive strength of $15 \%, 35 \%$ and $40 \%$ for mortars made with $(F),(R)$, and $(A)$ additive respectively. These results highlight the suitable behaviour of mortars made with a high amount of EPS after freezethaw cycles. The influence of the additives in 0\%EPS mortars subjected to freeze-thaw cycles is 
observed by comparing $(\mathrm{Sc})_{\text {cold }}$ for $0 \% \mathrm{EPS}$ with additives and the $(\mathrm{Sc})_{\text {cold }}$ for control mortar. It can be deduced that air-entraining agent $(\mathrm{A})$ reduces the compressive strength by $50 \%$, water retainer additive $(R)$ reduces it by $16 \%$, whereas superplasticizer additive $(F)$ increases the compressive strength by $81 \%$. The additive influence in EPS mortars subjected to freeze-thaw cycles is observed comparing $(\mathrm{Sc})_{\text {cold }}$ for $70 \%$ EPS with additives and the $(\mathrm{Sc})_{\text {cold }}$ corresponding to $70 \% \mathrm{EPS}$ mortar without additives. It can be deduced that air-entraining agent $(A)$ reduces the compressive strength $60 \%$ and superplasticizer additive (F) increases the compressive strength above than $40 \%$. The use of a water retainer additive does not modify significantly the compressive strength of these mortars after the freeze-thaw cycles. The combined influence of additives and freeze-thaw cycles can be seen by comparing (Sc) $)_{\text {cold }}$ values for 0\%EPS mortars and Sc value for control mortar. The greatest losses are observed in mortars with the air-entraining agent $(A)$. Mortars with water retainer additive $(\mathrm{R})$ show losses of $35 \%$. One again, only mortars with superplasticizer additive improve their compressive strength, in this case by around 35\%. EPS mortars show a similar trend: losses in compressive strength around $70 \%$ and $25 \%$ for mortars with $(A)$ and $(R)$ additive, respectively. Again, the highest compressive strength is obtained for EPS mortars made with superplasticizer $(F)$ additive. The higher workability and lower porosity of mortars made with (F) additive compared to mortars made with other studied additives could be the reason for this observed behaviour. 


\section{CONCLUSIONS}

The following are the conclusions of this study.

1. The capillary absorption coefficient of EPS mortars makes it possible to conclude that the presence of EPS in mortars improves their durability. The use of additives allows the fabrication of mortars with high EPS dosages and better durability when compared to a control mortar.

2. Mercury intrusion porosimetry is not a suitable technique for studying the microstructure of mortars made with EPS due to the inner porous structure of the EPS particles.

3. There were no clear relationships between impedance spectroscopy parameters, the open porosity, and the capillary absorption coefficient. Moreover, it was not posible to justify the observed trends using mercury intrusion porosimetry. For these reasons, it can be concluded that the presence of EPS in mortars, due to the polymeric nature and inner porous structure of the EPS, does not allow a suitable microstructure study using the equivalent circuits established in the literature for cementious materials. Future studies must be proposed to address this issue.

4. EPS has a positive effect on the compressive strength of mortars subjected to heat cycles. Improvements in the microstructure of cement pastes as well as in the cement paste-EPS interface may be the basis for the observed increase in compressive strength. The mortars with a highest dosage of EPS and superplasticizer additive are the most durable.

5. The presence of EPS in mortars improves and/or maintains their durability after freeze-thaw cycles. The EPS absorbs some of the crystallization pressure of ice, contributing to a reduction of mortar damage and an increase in durability. The optimum behaviour occurs in mortars made with superplasticizer additives.

\section{ACKNOWLEDGMENTS}

The authors wish to thank the Spanish Ministry of Science and Innovation and European Union (FEDER) for the BIA2007-61170 project funding, in the framework of which this work has been done, and the FPI scholarship (BES-2009-012166) award to Verónica Ferrándiz Mas which allows 
her to develop her doctoral thesis, which this present work is part. The authors also wish to thank Dr. Isidro Sánchez for his support with the impedance study and Holcim Morteros S.A., for the supply of cement and additives necessary for carrying out this study. 


\section{REFERENCES}

[1] Short A., Kinniburgh W. Lightweight Concrete. 3rd ed., London: Applied Science Publishers: 1978.

[2] Sussman V. Lightweight plastic-aggregate concrete. J Am Concr Inst Proc 1975; 72: 321-323.

[3] Ganesh Babu K, Saradhi Babu D. Behaviour of lightweight expanded polystyrene concrete containing silica fume. Cem Concr Res 2003; 33: 755-762.

[4] Ganesh Babu K, Saradhi Babu D. Properties of lightweight expanded polystyrene aggregate concretes containing fly ash. Cem Concr Res 2005; 35: 1218-1223.

[5] Tang WC, Lo Y, Nadeem A. Mechanical and drying shrinkage properties of structural-graded polystyrene aggregate concrete. Cem Concr Compos 2008; 30: 403-409.

[6] Bouvard D, Chaix JM, Dendievel R, Fazekas A, Létang JM, Peix G, et al. Characterization and simulation of microstructure and properties of EPS lightweight concrete. Cem Concr Res 2007; 37: 1666-1673.

[7] Madandoust R, Ranjbar MM, Mousavi SY. An investigation on the fresh properties of selfcompacted lightweight concrete containing expanded polystyrene. Construct Build Mater 2011; 25: 3721-3731.

[8] Laukaitis A, Zurauskas R, Keriene J. The effect of foam polystyrene granules on cement composite properties. Cem Concr Compos 2005; 27: 41-47.

[9] González Madariaga FJ, Lloveras Macia J. EPS (expanded poliestyrene) recycled bends mixed with plaster or stucco, some applications in building industry. Inf Constr 2008; 60; 509: 3543.

[10] García Santos A. PPF-reinforced, ESP-lightened gypsum plaster. Mater Construcc 2009; 59: 293: $105-124$.

[11] Wu HC, Sun P. New building materials from fly ash-based lightweight inorganic polymer. Construct Build Mater 2007; 21: 211-217. 
[12] Ferrándiz-Mas V, García-Alcocel E. Physical and Mechanical characterization of Portland cement mortars made with expanded polystyrene particles addition (EPS). Mater Construcc 2012; 62; 308: 547-566.

[13] UNE-EN 196-1:2005: "Methods of cement testing. Part 1: Determination of Mechanical strengths".

[14] UNE-EN 1015-3:2007: "Methods of test for mortars for masonry. Part 3. Determination of consistence of fresh mortar (by flow table)".

[15] UNE-EN 1015-18:2003: "Methods of test for mortars for masonry. Part 18. Determination of water absorption coefficient due to capillary action of hardened mortar".

[16] Cabeza M, Merino P, Miranda A, Nóvoa XR, Sánchez I. Impedance spectroscopy study of hardened Portland cement paste. Cem Concr Res 2002; 32: 881-891.

[17] Sanchez I, Nóvoa XR, de Vera G, Climent MA. Microestructural modifications in Portland cement concrete due to forced ionic migration tests. Study by impedance spectroscopy. Cem Concr Res 2008; 38: 1015-1025.

[18] Sánchez I, López MP, Ortega JM, Climent MA. Impedance spectroscopy: An efficient tool to determine the non-steady-state chloride diffusion coefficient in building materials. Mater Corros 2011; 62: 139-145.

[19] Cabeza M, Keddam M, Nóvoa XR, Sánchez I, Takenouti H. Impedance spectroscopy to characterize the pore structure during the hardening process of Portland cement paste. Electrochim Acta 2006; 51: 1831-1841.

[20] Ortega J.M, Albaladejo A, Pastor J.L, Sánchez I, Climent M.A. Influence of using slag cement on the microstructure and durability related properties of cement grouts for micropiles. Construct Build Mater 2013; 38: 84-93.

[21] Cabeza M, Merino P, Nóvoa XR, Sánchez I. Electrical effects generated by mechanical loading of hardened Portland cement paste. Cem Concr Compos 2003, 25: 351-356.

[22] Washburn EW. Note on method of determining the distribution of pore sizes in porous materials. Proc Nat Acad Sci U.S.A. 1921; 7; 4: 115-116.

[23] UNE 67028 EX: 1997. Clay bricks. Freezing test. 
[24] Puertas F; Santos H, Palacios M, Martínez-Ramirez S, Polycarboxylate superplasticizer admixtures: effect on hydration, microstructure and rheological behavior in cement pastes. Adv Cem Res 2005; 17; 2: 77-89.

[25] Monografía ACHE no 16, "Manual de tecnología de aditivos para hormigón”, Asociación científico-técnica del hormigón estructural; 2010.

[26] Chekaev A. Variational methods for structural optimisation. Springer Verlag. New York. 2000. p 158-160. 


\section{FIGURE CAPTIONS}

Figure 1: Impedance measurement on an EPS mortar sample. (a) Contacting method: The sample is placed between two electrodes for application of an electrical current. (b) Non-contacting method: The sample is placed between two insulating films that are in contact with the electrodes that provide the electrical current.

Figure 2: Equivalent circuits proposed by Cabeza et al. [16]. (a) Equivalent circuit used to model the data using the contacting method. (b) Equivalent circuit used to model the data using the noncontacting method.

Figure 3. Capillary absorption coefficient $\left(\mathrm{C}_{90}\right)$, as a function of the percentage and type of EPS in mortar, with a 95\% confidence interval.

Figure 4. Capillary absorption coefficient $\left(\mathrm{C}_{90}\right)$ as a function of the type of EPS in mortars made with $0 \%$ and $70 \%$ EPS and different additives, with a $95 \%$ confidence interval. (A: air-entraining agent; R: water retainer additive; F: superplasticizer additive)

Figure 5. Pore size distribution obtained through mercury intrusion porosimetry in $0 \%$ EPS mortars made with additives (A: air-entraining agent; $\mathrm{R}$ : water retainer additive; F: superplasticizer additive)

Figure 6. Compressive strength of mortars made with various dosages of EPSw with a $95 \%$ confidence interval, where: Sc (before cycles), $(\mathrm{Sc})_{\text {heat }}$ (after heat cycles) and $(\mathrm{Sc})_{\text {cold }}$ (after freezethaw cycles).

Figure 7. Electron microscope images of a mortar made with $70 \%$ of EPSw subjected to heat cycles. a) EPS particles in mortar. b) Fine polymer wall that separates the cells in EPS particle c) EPS particle with adequate adherence to paste in mortars that undergo heat cycles.

Figure 8. Compressive strength of mortars made with $0 \%$ and $70 \%$ EPSw with additives with a 95\% confidence interval, where: Sc (before cycles), (Sc) $)_{\text {heat }}$ (after heat cycles) and (Sc) cold (after freeze-thaw cycles). 
Table 1. Properties of the various types of EPS used in mortar preparation.

Table 2. EPS and additive dosages used in the studied mortars.

Table 3. Open porosity (section 2.2.4) and total porosity measured by mercury intrusion porosimetry (MIP) after a 120 day curing period.

Table 4. Impedance spectroscopy parameters $\left(R_{1}, R_{2}, C_{1}, C_{2}\right)$ and open porosity computed after a 120 day curing period as well as the capillary absorption coefficient $\left(\mathrm{C}_{90}\right)$ for mortars made with various types of EPS and additives. 
Table 1. Properties of the various types of EPS used in mortar preparation.

\begin{tabular}{ccccc}
\hline EPS type & Waste & $\begin{array}{c}\text { Particle diameter } \\
(\mathbf{m m})\end{array}$ & $\begin{array}{c}\text { Particle } \\
\text { geometry }\end{array}$ & Density $\left(\mathbf{g} / \mathbf{c m}^{\mathbf{3}}\right)$ \\
\hline EPSc & No & $>3$ & spherical & 0,008 \\
EPSpex & No & $<3$ & spherical & 0,052 \\
EPSw & Yes & $<1$ & irregular & 0,013 \\
\hline
\end{tabular}

Table2. EPS and additive dosages used in the studied mortars.

\begin{tabular}{|c|c|c|c|c|}
\hline Type of EPS & $\begin{array}{c}\text { EPS } \\
(\mathbf{v} / \mathbf{v} \%)\end{array}$ & $\begin{array}{c}\text { Air-entraining } \\
\text { agent (A) } \\
\text { (w/w \%) }\end{array}$ & $\begin{array}{c}\text { Water retainer additive } \\
(\mathrm{R}) \\
(\mathbf{w} / \mathbf{w} \%)\end{array}$ & $\begin{array}{l}\text { Superplasticizer } \\
\text { additive (F) } \\
(\mathbf{w} / \mathbf{w} \%) \\
\end{array}$ \\
\hline \multirow{2}{*}{ EPSc } & $0,10,30,50,70$ & 0 & 0 & 0 \\
\hline & 0,70 & 0,8 & 0,3 & 0,1 \\
\hline \multirow{2}{*}{ EPSpex } & $0,10,30,50,70$ & 0 & 0 & 0 \\
\hline & 0,70 & 0,8 & 0,3 & 0,9 \\
\hline \multirow{2}{*}{ EPSw } & $0,10,30,50,70$ & 0 & 0 & 0 \\
\hline & 0,70 & 0,8 & 0,3 & 0,5 \\
\hline
\end{tabular}

Table 3. Open porosity (section 2.2.4) and total porosity measured by mercury intrusion porosimetry (MIP) after a 120 day curing period.

\begin{tabular}{ccc}
\hline Mortar & $\begin{array}{c}\text { Open porosity } \\
(\%)\end{array}$ & $\begin{array}{c}\text { Total porosity by } \\
\text { MIP (\%) }\end{array}$ \\
\hline control & 13,4 & 15,5 \\
$70 \%$ EPSc & 11,3 & 40,2 \\
$70 \%$ EPSpex & 11,4 & 33,7 \\
$70 \%$ EPSw & 13,4 & 32,4 \\
$70 \%$ EPSw + 0,8\% A & 12,4 & 44,8 \\
$70 \%$ EPSw+ 0,3\% R & 14,4 & 33,9 \\
70\% EPSw+ 0,5\% F & 13,3 & 33,4 \\
\hline (A: air-entraining agent; R: water retainer additive; F: superplasticizer additive)
\end{tabular}

Table 4. Impedance spectroscopy parameters $\left(R_{1}, R_{2}, C_{1}, C_{2}\right)$ and open porosity computed after a 120 day curing period as well as the capillary absorption coefficient $\left(\mathrm{C}_{90}\right)$ for mortars made with various types of EPS and additives.

\begin{tabular}{|c|c|c|c|c|c|c|}
\hline Mortar & $\mathbf{R}_{1}(\Omega)$ & $\mathbf{R}_{2}(\Omega)$ & $C_{1}(p F)$ & $\mathrm{C}_{2}(\mathrm{pF})$ & $\begin{array}{c}\text { Open porosity } \\
(\%)\end{array}$ & $\begin{array}{c}\mathrm{C}_{90} \\
\left(\mathrm{Kg} / \mathrm{m}^{2} \min ^{0.5}\right)\end{array}$ \\
\hline EPS & $7,75 \mathrm{e}^{29}$ & $9,99 e^{19}$ & 5,69 & 0,146 & - & - \\
\hline Control & 208,4 & 391,0 & 26,8 & 427 & 13,4 & 0,210 \\
\hline $70 \%$ EPSc & 234,4 & 271,0 & 39,4 & 293 & 11,3 & 0,168 \\
\hline $70 \%$ EPSc $+0.8 \% A$ & 198,5 & 270,7 & 18,7 & 153 & 11,9 & 0,153 \\
\hline $70 \%$ EPSc +0.3R & 121,2 & 199,2 & 20,8 & 316 & 12,6 & 0,093 \\
\hline $70 \%$ EPSc $+0.1 F$ & 246,5 & 180,8 & 18,8 & 143 & 12,1 & 0,122 \\
\hline 70\% EPSpex & 179,8 & 269,7 & 14,0 & 251 & 11,4 & 0,232 \\
\hline 70\% EPSpex+0.8\%A & 195,7 & 144,2 & 18,3 & 136,5 & 11,2 & 0,073 \\
\hline $70 \%$ EPSpex +0.3R & 135,9 & 462,6 & 17,5 & 348 & 13,3 & 0,103 \\
\hline $70 \%$ EPSpex+0.9F & 131,9 & 137,3 & 18,4 & 109 & 11,0 & 0,092 \\
\hline $70 \%$ EPSw & 219,0 & 372,6 & 20,7 & 455 & 13,4 & 0,205 \\
\hline $70 \%$ EPSw+0.8\%A & 87,8 & 111,0 & 16,1 & 74,0 & 12,4 & 0,082 \\
\hline $70 \%$ EPSw +0.3R & 86,7 & 128,3 & 20,8 & 342 & 14,4 & 0,112 \\
\hline $70 \%$ EPSw +0.5F & 87,6 & 349,0 & 23,7 & 398 & 13,3 & 0,137 \\
\hline
\end{tabular}

(A: air-entraining agent; $R$ : water retainer additive; $F$ : superplasticizer additive) 

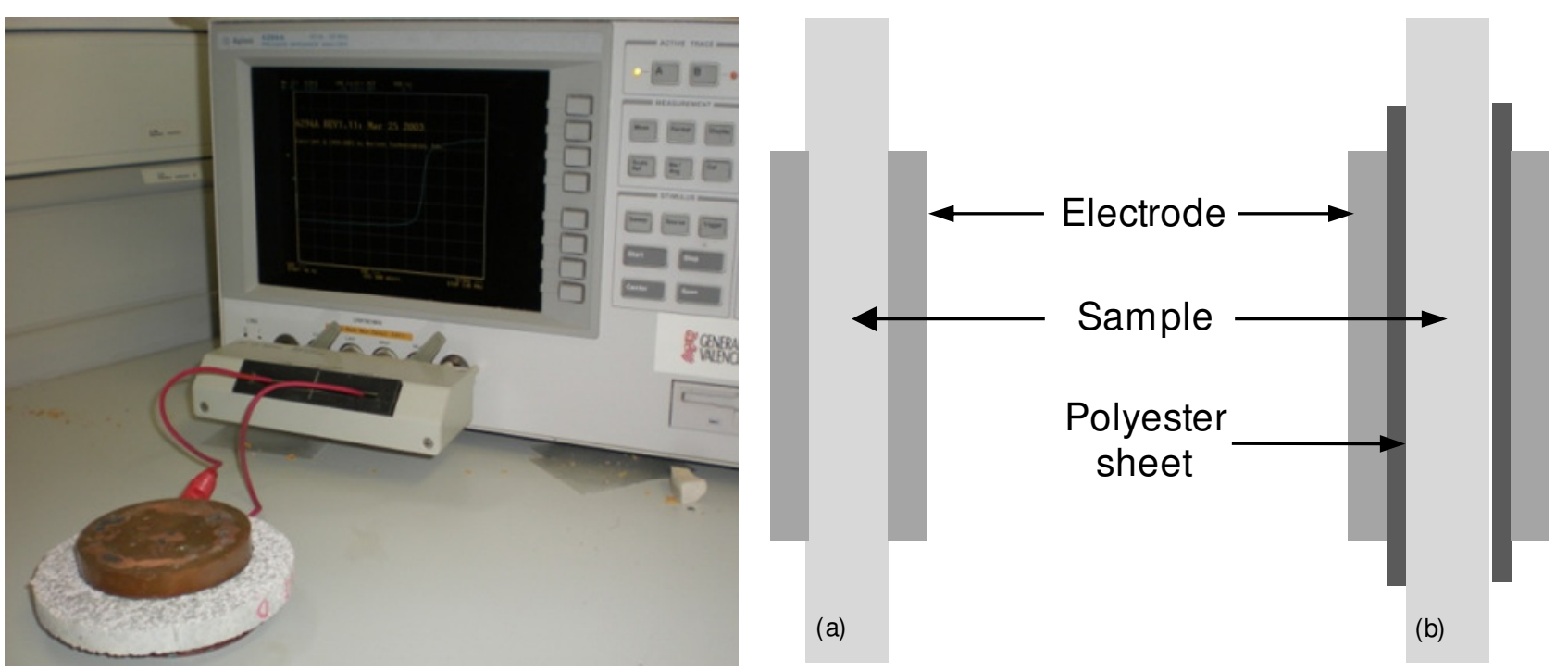

Figure 1: Impedance measurement on an EPS mortar sample. (a) Contacting method: The sample is placed between two electrodes for application of an electrical current. (b) Non-contacting method: The sample is placed between two insulating films that are in contact with the electrodes that provide the electrical current.
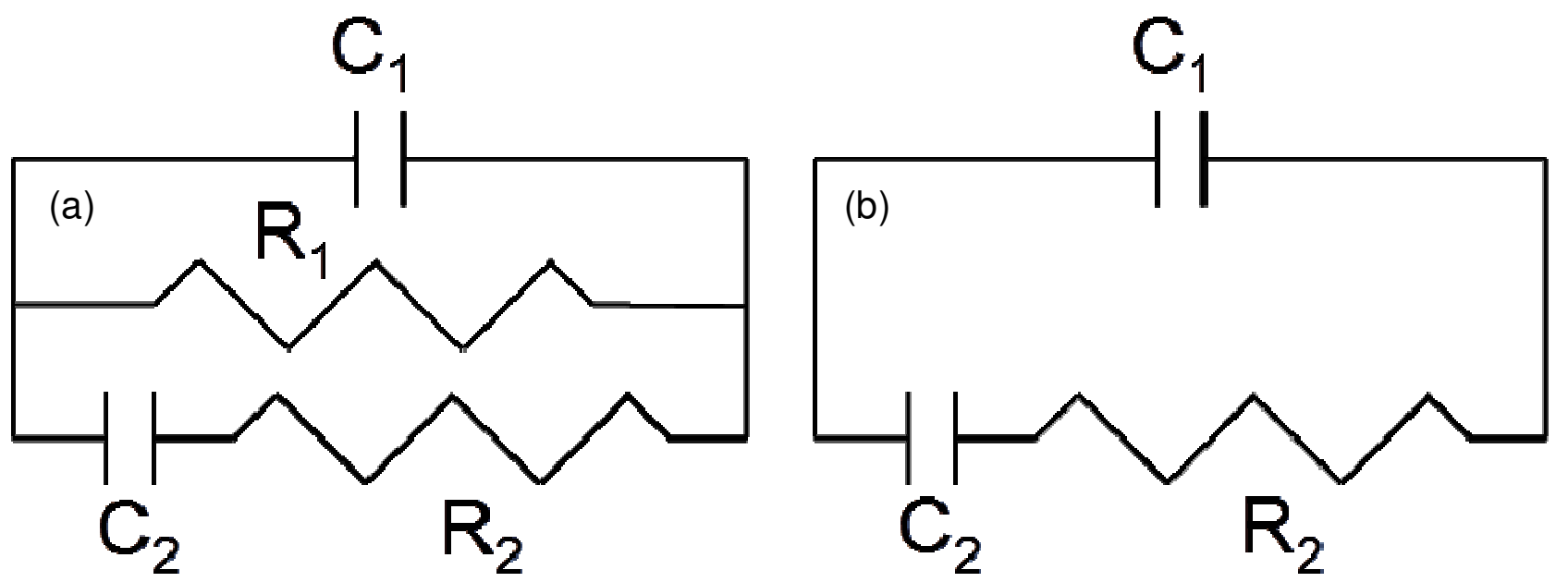

Figure 2: Equivalent circuits proposed by Cabeza et al. [16]. (a) Equivalent circuit used to model the data using the contacting method. (b) Equivalent circuit used to model the data using the noncontacting method. 


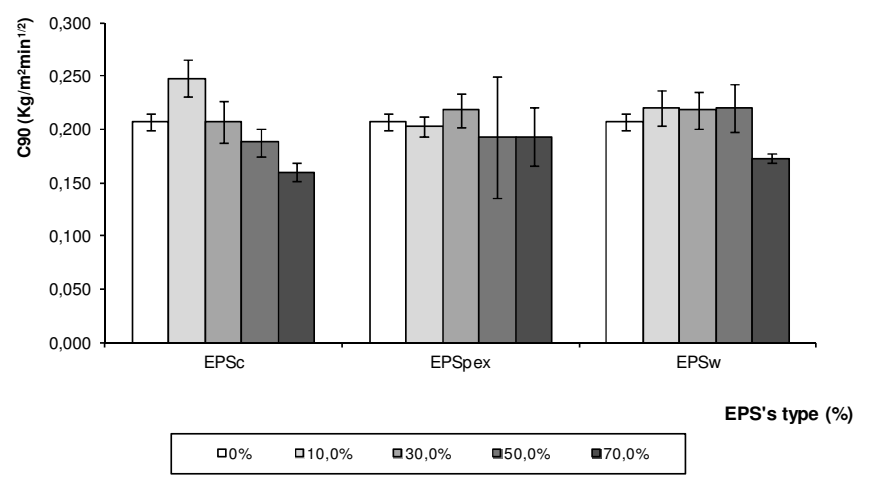

Figure 3. Capillary absorption coefficient $\left(\mathrm{C}_{90}\right)$, as a function of the percentage and type of EPS in mortar, with a $95 \%$ confidence interval.

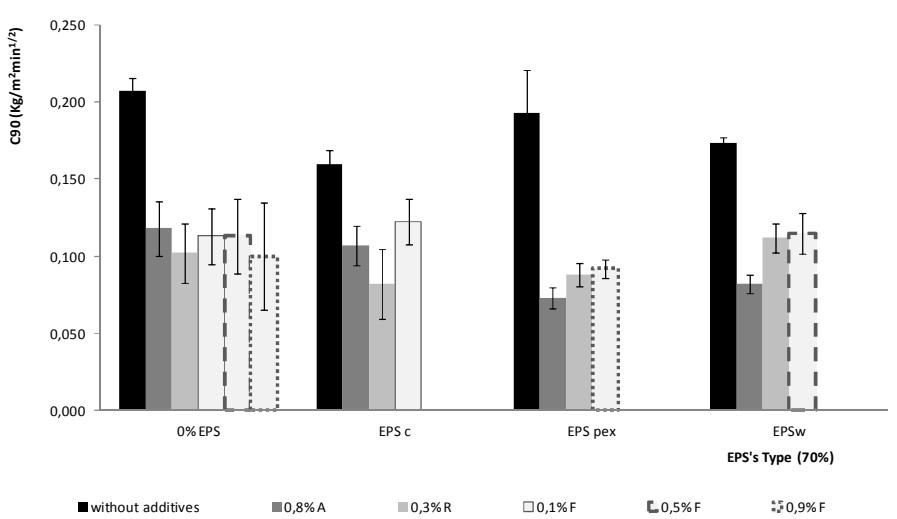

Figure 4. Capillary absorption coefficient $\left(\mathrm{C}_{90}\right)$ as a function of the type of EPS in mortars made with $0 \%$ and $70 \%$ EPS and different additives, with a $95 \%$ confidence interval. (A: air-entraining agent; R: water retainer additive; F: superplasticizer additive) 


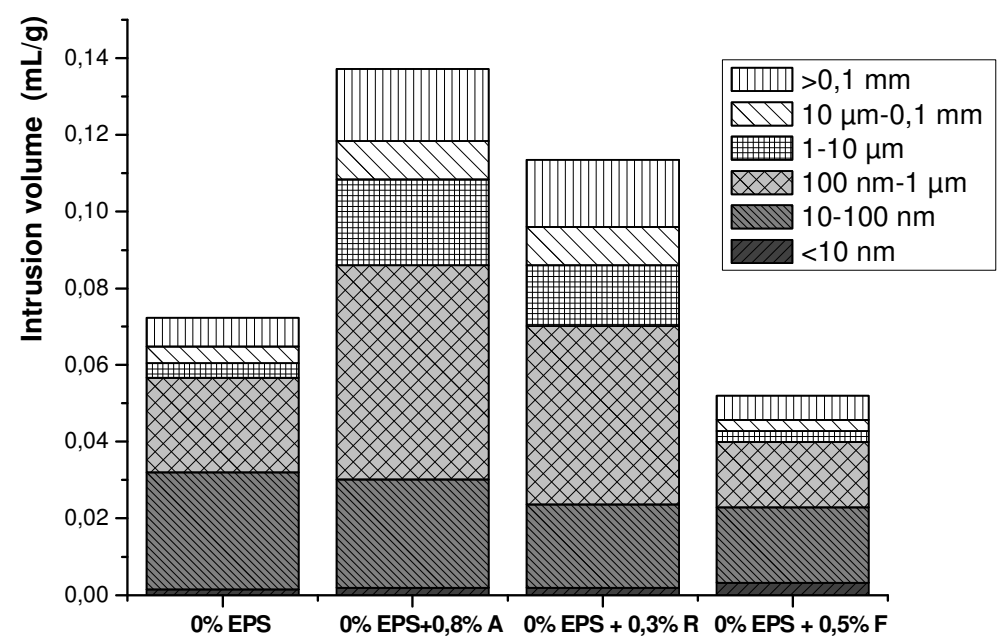

Figure 5. Pore size distribution obtained through mercury intrusion porosimetry in 0\% EPS mortars made with additives (A: air-entraining agent; R: water retainer additive; F: superplasticizer additive) 


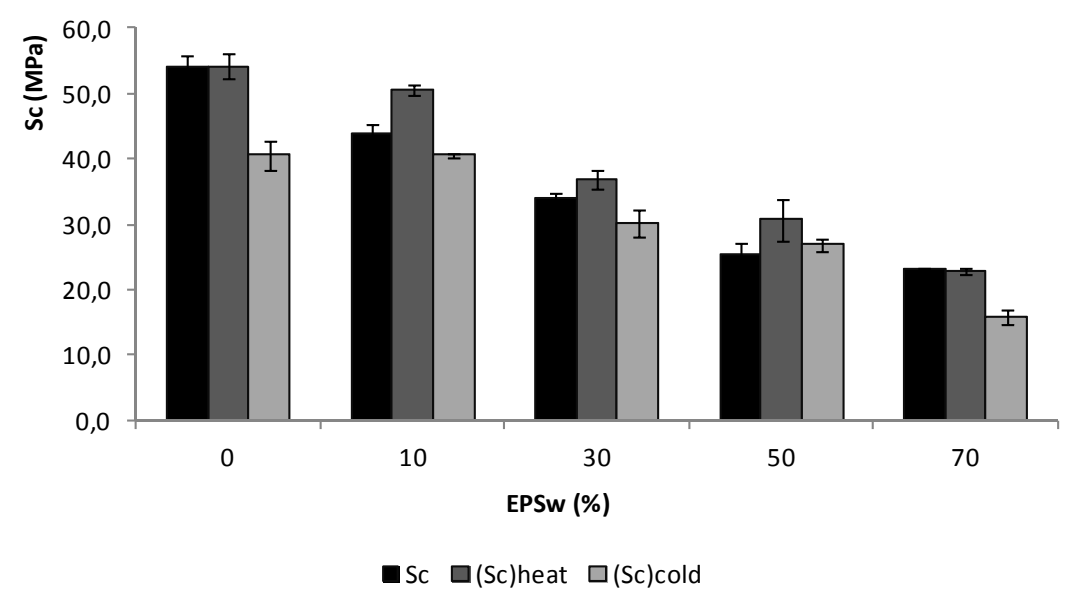

Figure 6. Compressive strength of mortars made with various dosages of EPSw with a 95\% confidence interval, where: Sc (before cycles), (Sc) $)_{\text {heat }}$ (after heat cycles) and (Sc) cold (after freezethaw cycles).
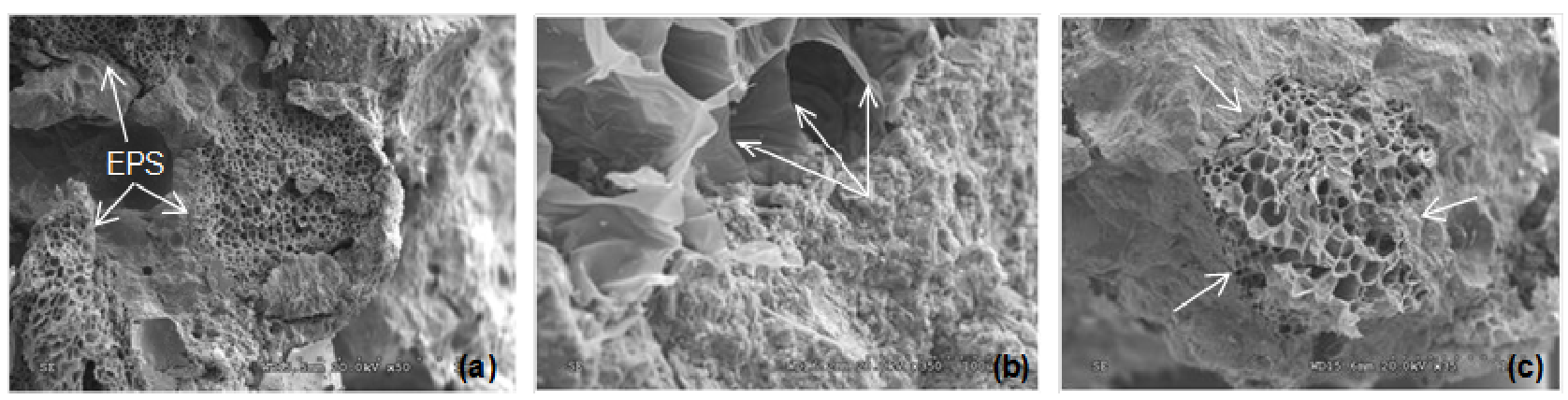

Figure 7. Electron microscope images of a mortar made with $70 \%$ of EPSw subjected to heat cycles. a) EPS particles in mortar. b) Fine polymer wall that separates the cells in EPS particle c) EPS particle with adequate adherence to paste in mortars that undergo heat cycles. 


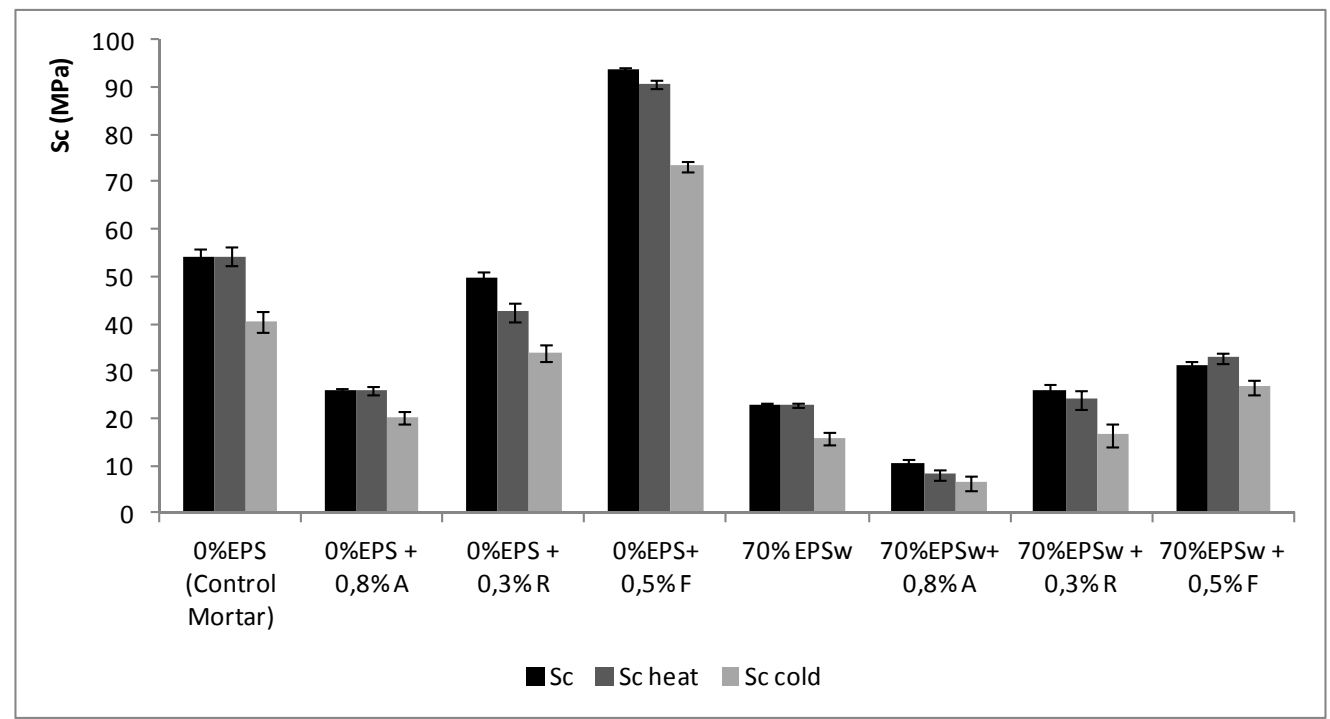

Figure 8. Compressive strength of mortars made with $0 \%$ and $70 \%$ EPSw with additives with a 95\% confidence interval, where: Sc (before cycles), (Sc) heat (after heat cycles) and (Sc) cold (after freeze-thaw cycles) 